\title{
DER GEIST
}

DER UNRUHE 


\section{LiteratuRForschUNG}

Herausgegeben vom

Zentrum für Literaturforschung

von Eberhard Lämmert 


\section{DER GEIST DER UNRUHE}

1968 im Vergleich

Wissenschaft - Literatur - Medien

Herausgegeben von Rainer Rosenberg, Inge Münz-Koenen und Petra Boden unter Mitarbeit von Gabriele Gast

Akademie Verlag 
Gedruckt mit Unterstützung der Deutschen Forschungsgemeinschaft.

Die Deutsche Bibliothek - CIP-Einheitsaufnahme

\section{Der Geist der Unruhe :}

1968 im Vergleich ; Wissenschaft - Literatur - Medien /

hrsg. von Rainer Rosenberg, Inge Münz-Koenen und

Petra Boden. Unter Mitarb. von Gabriele Gast. -

Berlin : Akad. Verl., 2000

(Literaturforschung)

ISBN 3-05-003480-7

(C) Akademie Verlag GmbH, Berlin 2000

Das eingesetzte Papier ist alterungsbeständig nach DIN/ISO 9706.

Alle Rechte, insbesondere die der Ubersetzung in andere Sprachen, vorbehalten. Kein Teil des Buches darf ohne Genehmigung des Verlages in irgendeiner Form - durch Photokopie, Mikroverfilmung oder irgendein anderes Verfahren - reproduziert oder in eine von Maschinen, insbesondere von Datenverarbeitungsmaschinen, verwendbare Sprache übertragen oder übersetzt werden.

Lektorat: Peter Heyl

Gestaltung und Satz: Petra Florath, Berlin

Druck: GAM Media GmbH, Berlin

Bindung: Druckhaus "Thomas Müntzer" GmbH, Bad Langensalza

Printed in the Federal Republic of Germany 